\title{
Some Aspects of Variable Amplitude Fatigue
}

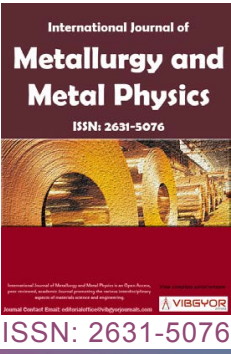

\section{A Gwider ${ }^{1}$ and N Ranganathan ${ }^{2 *}$}

${ }^{1}$ Phd Student, University François Rabelais de Tours, France

${ }^{2}$ Emeritus Professor, Former Director Laboratory of Mechanics and Rheology, Laboratoire Gabriel Lamé, University François Rabelais de Tours, France

\begin{abstract}
Fatigue crack growth behavior of selected aluminum alloys under variable amplitude loading is discussed in this study, based principally on experimental observations. The tests include single overloads tests in different environments, and tests using an aircraft wing loading spectrum. It is shown that conditions favoring a planar slip behavior lead to very high delays as opposed to conditions leading to multiple slip behavior. An anomalous effect is observed in an aluminum Lithium alloy.
\end{abstract}

\section{Introduction}

Understanding of the fatigues resistance of materials under variable amplitude loading conditions is primordial for structural applications. This aspect is critical especially for aircraft applications. There have been numerous examples catastrophic fatigue failures such as the comet aircraft in the 1950s or the McDonald Douglas DC10 in the year 1979 or the Aloha airlines accident of a Boeing 737 aircraft in 1983.

Aircraft materials are subjected to fatigue testing using test specimens, according to standard test procedures for constant amplitude testing $[1,2]$. Such tests permit the determination of the evolution of the crack growth rate per cycle, da/ $\mathrm{dN}$, versus the stress intensity factor amplitude $\Delta \mathrm{K}$. Special procedures exist for the determination of the threshold for crack propagation.

But loads in real life situations are not constant amplitudes. In an aircraft wing lower surface (the case referred to here), the stresses are compressive on this part, with the aircraft on ground. When the aircraft takes off, stresses become positive with the addition lift forces. In the cruise condition, gust and maneuver loads add to small variations of stresses around the mean stress under cruising conditions. The aircraft then lands and stresses become negative. This is one kind of variable amplitude loading. Some standard spectra have been developed representing certain structures such as:

- TWIST or MINITWIST - Transport aircraft lower wing root.

*Corresponding author: N Ranganathan, Emeritus Professor, Former Director Laboratory of Mechanics and Rheology, Laboratoire Gabriel Lamé, E.A.7494, University François Rabelais de Tours, Polytech Tours, 7 Avenue Marcel Dassault, 37200 Tours, France

Accepted: May 21, 2019; Published: May 23, 2019

Copyright: (C) 2019 Gwider A, et al. This is an open-access article distributed under the terms of the Creative Commons Attribution License, which permits unrestricted use, distribution, and reproduction in any medium, provided the original author and source are credited.

Gwider and Ranganathan. Int J Metall Met Phys 2019, 4:032 
- FALSTAFF - Fighter aircraft lower wing root.

- HELIX - Hinged helicopter rotor.

- TURBISTAN - Disks in fighter aircraft engine.

- WISPER Horizontal axis wind turbine blades [3-5].

These spectra are generalized load sequences but in practice, each industry develops its own load sequences for testing and qualification of products and structures.

But no standardized procedures are available for variable amplitude testing, mostly due to the complexity of the processes involved. The complexities include maintaining load accuracy, the selection of an adequate test sample representative of the structure, full scale fatigue testing under selected spectra and data analysis technique $[4,6]$. For data analysis, another complexity arises - what is the representative mechanical parameter that is valid for a spectrum load? A mean load, a RMS value or the maximum load in the spectrum?

In this paper, the results of variable amplitude fatigue crack growth behavior of a few selected aluminum alloys are presented and discussed.

\section{Experimental Details}

\section{Materials tested}

The nominal compositions and static properties of materials tested, for fatigue crack growth behavior are given in the Table $1 \mathrm{a}$ and Table $1 \mathrm{~b}$ below:

- In the Al-Li 8090 alloy, traces of Zr are present.

- The 7075 alloy is tested in three conditions: T351, T651 and T7351.
- The 2024 alloy is tested in the T351 condition and the 8090 alloy in the T651 condition.

The different heat treatment conditions are described below:

- T351 condition (2024 and 7075 alloys) - This is the under-aged condition - solution heat treated, cold worked and naturally aged. The main precipitates are Guinier-Preston zones.

- T651 condition (7075 and 8090 alloys) - This corresponds to the peak aged condition-Solution heat treated, stress relieved by stretching then artificially aged to peak hardness.

- In the 7075 alloy, the precipitates are $\mathrm{Mg}_{11} \mathrm{Zn}_{11} \mathrm{Al}$, of size less than $60 \mathrm{~A}^{\circ}$ and coherent with the matrix.

- In the 8090 alloy, the precipitates are $\delta^{\prime}\left(\mathrm{Al}_{3} \mathrm{Li}\right)$ and $\mathrm{S}^{\prime}\left(\mathrm{Al}_{2} \mathrm{CU} \mathrm{Mg}\right)$ coherent with the matrix.

- The T7351 condition (overaged), In this overaged condition the precipitates are $\mathrm{Mg} \mathrm{Zn_{2 }}$ and $\mathrm{Mg}_{32}$ $\left((\mathrm{AlZn})_{49}\right)$ - They are non coherent with the matrix.

The solution het treatment temperature is between 480 and $540{ }^{\circ} \mathrm{C}$, the ageing temperature is typically $120^{\circ} \mathrm{C}$ and ageing time depends upon the T6 or T73 temper [7].

\section{Experimental details}

The tests were conducted using compact tension specimens $6 \mathrm{~mm}$ (thick and $35 \mathrm{~mm}$ wide for the 7075 and 8090 alloys. The 2024 alloy was tested using specimens $12 \mathrm{~mm}$ thick an $75 \mathrm{~mm}$ wide $[8,9]$. The tests were carried out mostly in ambient

Table 1a: Composition (in \%wt.) of the studied alloys (Al not indicated).

\begin{tabular}{|l|l|l|l|l|l|l|l|l|l|}
\hline Alloy & Zn & Mg & Cu & Cr & Fe & Si & Mn & Ti & Li \\
\hline 2024 & 0.04 & 1.5 & 4.46 & 0.01 & 0.22 & 0.1 & 0.66 & 0.02 & - \\
\hline 7075 & 5.7 & 2.43 & 1.5 & 0.2 & 0.21 & 0.16 & 0.04 & 0.04 & - \\
\hline 8090 & - & 0.55 & 1.14 & - & 0.05 & 0.03 & 0.1 & 0.03 & 2.34 \\
\hline
\end{tabular}

Table 1b: Nominal mechanical properties.

\begin{tabular}{|l|l|l|l|l|}
\hline Alloy & Young's Modulus (GPa) & Yield strength (MPa) & Ultimate Tensile Strength (MPa) & Elongation (\%) \\
\hline 2024 T351 & 73 & 300 & 500 & 16 \\
\hline 7075 T351 & 70 & 458 & 583 & 10.6 \\
\hline 7075 T651 & 71.1 & 527 & 590 & 11 \\
\hline 7075 T7351 & 70.9 & 470 & 539 & 11.7 \\
\hline 8090 T651 & 81.2 & 430 & 480 & 13 \\
\hline
\end{tabular}




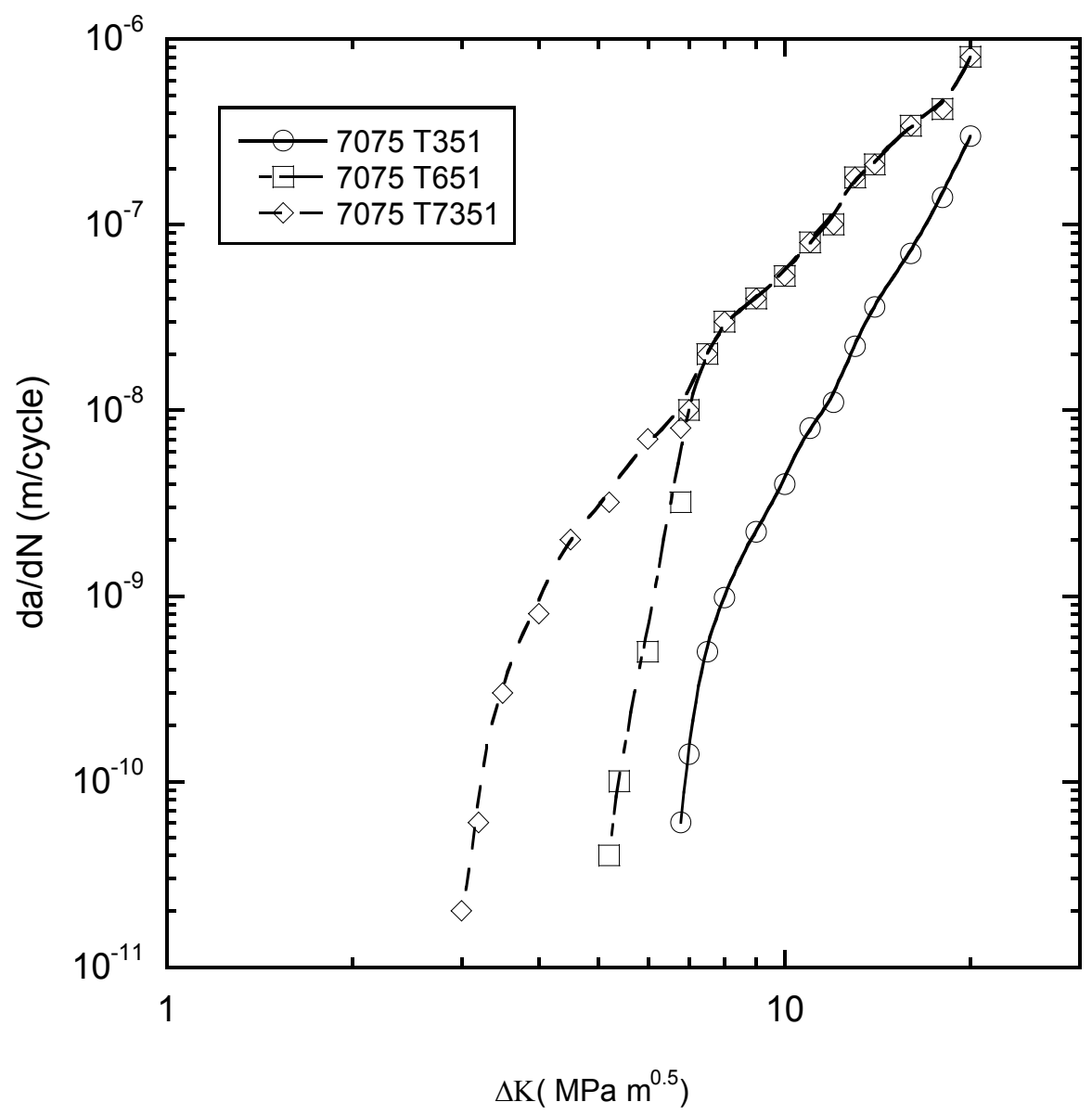

Figure 1: Constant amplitude behavior of the 7075 alloy in vacuum.

air - some tests were carried out in secondary vacuum. The test frequency was $20 \mathrm{HZ}$ in air $35 \mathrm{~Hz}$ in vacuum.

The overload test corresponds to $100 \%$ overloads, at a baseline load ratio of 0.1 .

The spectrum tests in air were carried out with a home made computer program at a frequency of $10 \mathrm{~Hz}$. Crack length was monitored optically on the polished surface with a traveling microscope $(25 \mathrm{x})$ with a resolution of $1 \mathrm{~m}$.

Crack growth rate is determined using the secant method (1).

$$
d a / d N=\left(a_{i+1}-a_{i}\right) /\left(N_{i+1}-N_{i}\right)
$$

Where $a_{i}$ is the crack length at cycle $N_{i}$ and $a_{i+1}$, the crack length at cycle $\mathrm{N}_{i+1}$. For flight simulations tests, $\mathrm{N}_{\mathrm{i}}$ and $\mathrm{N}_{\mathrm{i}+1}$ represent flight numbers.

\section{Different data analyzed}

The following data will be discussed in this paper:

a) Constant amplitude crack growth b) Post overload behavior

c) Crack growth under a flight simulation spectrum.

\section{Experimental Results}

\section{Constant amplitude crack growth behavior}

In aluminum alloys, previous studies have shown that tests in vacuum are more representative of intrinsic material behavior. The behavior of the 7075 alloy in the three heat treatment conditions are shown in Figure 1.

It can be seen here that the highest crack growth resistance (that is highest threshold value) is obtained in the under-aged T351 condition and the lowest resistance is obtained for the overaged T7351 condition. An intermediate behavior is observed on the peak-aged T651 condition. This is attributed to planar slip activation in the underaged condition and multiple slip in the Over-aged condition In the peak aged condition a change in slip activity takes place - moderate to high $\Delta K$, multiple slip and lower crack growth resistance as opposed to planar slip at low $\Delta K$ levels, near 


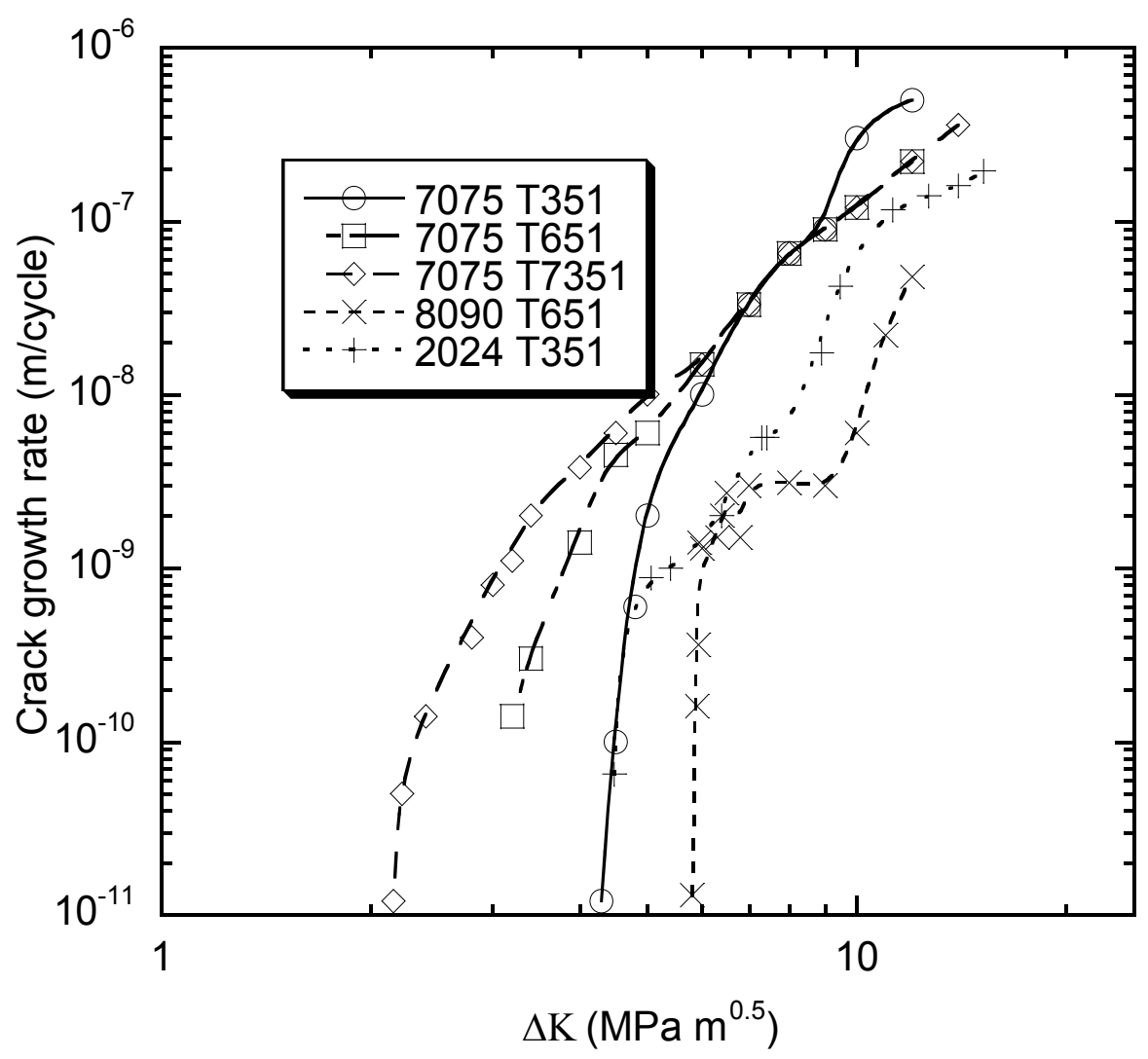

Figure 2: Constant amplitude crack growth of the studied alloys in air.

Table 2: The threshold values, $\Delta \mathrm{K}_{\mathrm{th}}$ for the studied alloys at a load ratio of 0.1 .

\begin{tabular}{|l|l|l|l|l|l|}
\hline Alloy & $\mathbf{8 0 9 0}$ T651 & $\mathbf{2 0 2 4}$ T351 & 7075 T351 & 7057 T651 & 7075 T7351 \\
\hline$\Delta \mathrm{K}_{\mathrm{th}}-$ Mpa m $^{0.5}$ & 5.8 & 4.3 & 4.2 & 3.1 & 2.2 \\
\hline
\end{tabular}

Table 3: Number of delay cycles at a baseline $\Delta \mathrm{K}$ of $10 \mathrm{Mpa} \mathrm{m}^{0.5}$.

\begin{tabular}{|l|l|l|l|l|l|}
\hline Alloy & 8090 T651 & 2024 T351 & 7075 T351 & 7057 T651 & 7075 T7351 \\
\hline$N_{d}$ cycles & 80000 & 20000 & 20000 & 6000 & 3000 \\
\hline
\end{tabular}

threshold $[8,10]$.

Now, the constant amplitude behavior in air of all the studied alloys are presented in Figure 2.

It can be seen that the threshold value is the highest for the Al Li 8090 alloy, while the lowest threshold is observed for the 7075 T7351 alloy. One can also from Figure 2, that the near threshold crack growth resistance follows the same order as that shown in Table 2.

\section{Post overload behavior}

The application of a single overload, generally leads to crack deceleration and even crack arrest and the understanding of the post overload behavior is important for aircraft type materials. This ef- fect is quantified in terms of the number of delay cycles, $\mathrm{N}_{\mathrm{d}}$, representing the number of cycles for a crack to attain the pre-overload crack kinetics after the overload application [11,12].

The evolution of $N_{d}$ with respect to baseline $\Delta K$ is shown in Figure 3.

The tests correspond to $100 \%$ overloads at a baseline load ratio of 0.1 . For example at a $\Delta K$ of $10 \mathrm{Mpa} \mathrm{m}^{0.5}$, the applied overload corresponds to a $\Delta \mathrm{K}$ of $20 \mathrm{Mpa} \mathrm{m}^{0.5}$. After this spike applied, the pre-overload cycling is resumed and the crack growth monitored to apprehend the delay behavior. The higher the delay is, more resistant is a material. In this respect, one can easily apprehend the fact the delays is the highest for the 8090 alloy throughout the covered $\Delta \mathrm{K}$ range, while the low- 


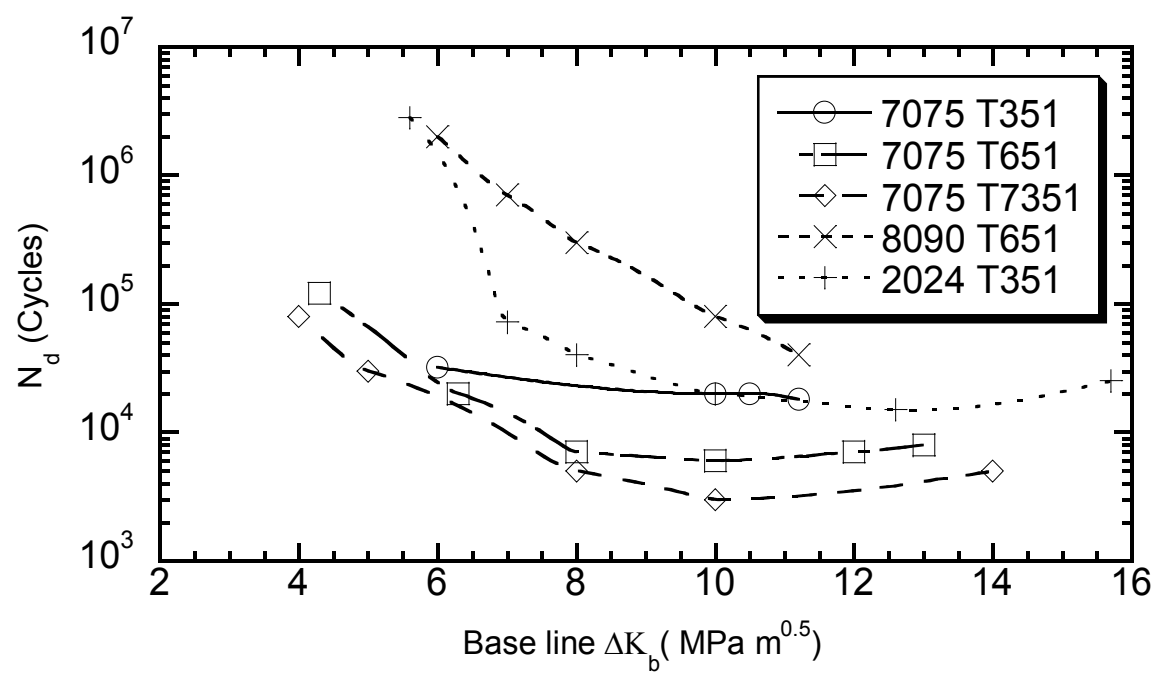

Figure 3: Number of delay cycles for the different alloys.

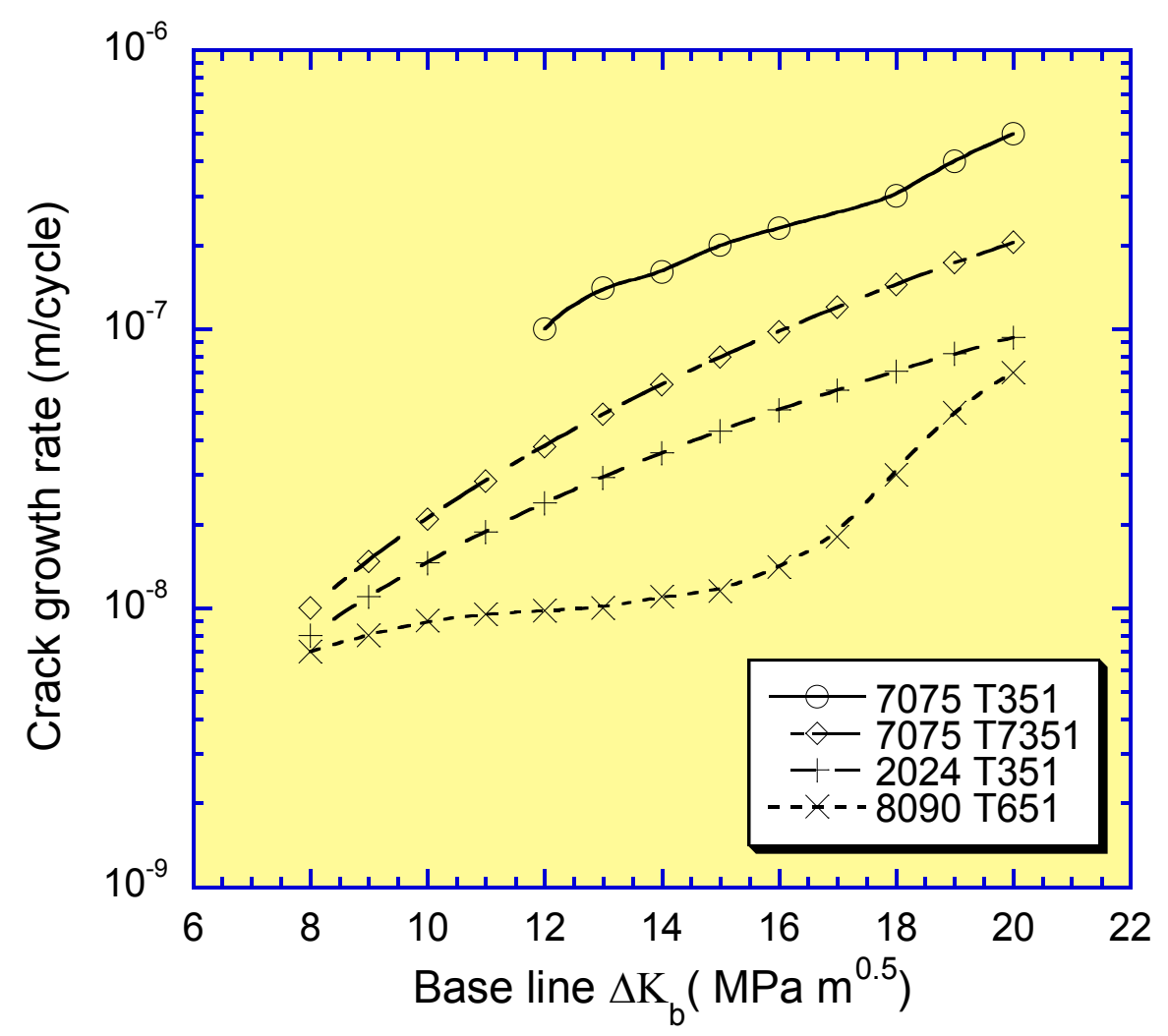

Figure 4: Repeated overload tests.

est delay is observed for the 7075 T7351 alloy. The number of delay cycles at a baseline $\Delta K$ of 10 is given in Table 3.

Comparing Table 2 and Table 3, we get the same classification in terms of delay cycles as in terms of threshold values. This confirms that, after an overload near threshold conditions exist at the crack tip [6] and a material with stronger near threshold resistance has a higher delay.

\section{Repeated overload tests}

The results of repeated overload tests, conducted in air, are given in Figure 4. The block type studied here contains 999 cycles at a baseline loading at an $\mathrm{R}$ ratio of 0.1 and an overload of $70 \%[6,8]$. Under such conditions the 7075 alloy in the T351 has the least resistance. The 7075 T7351 and the 2024 

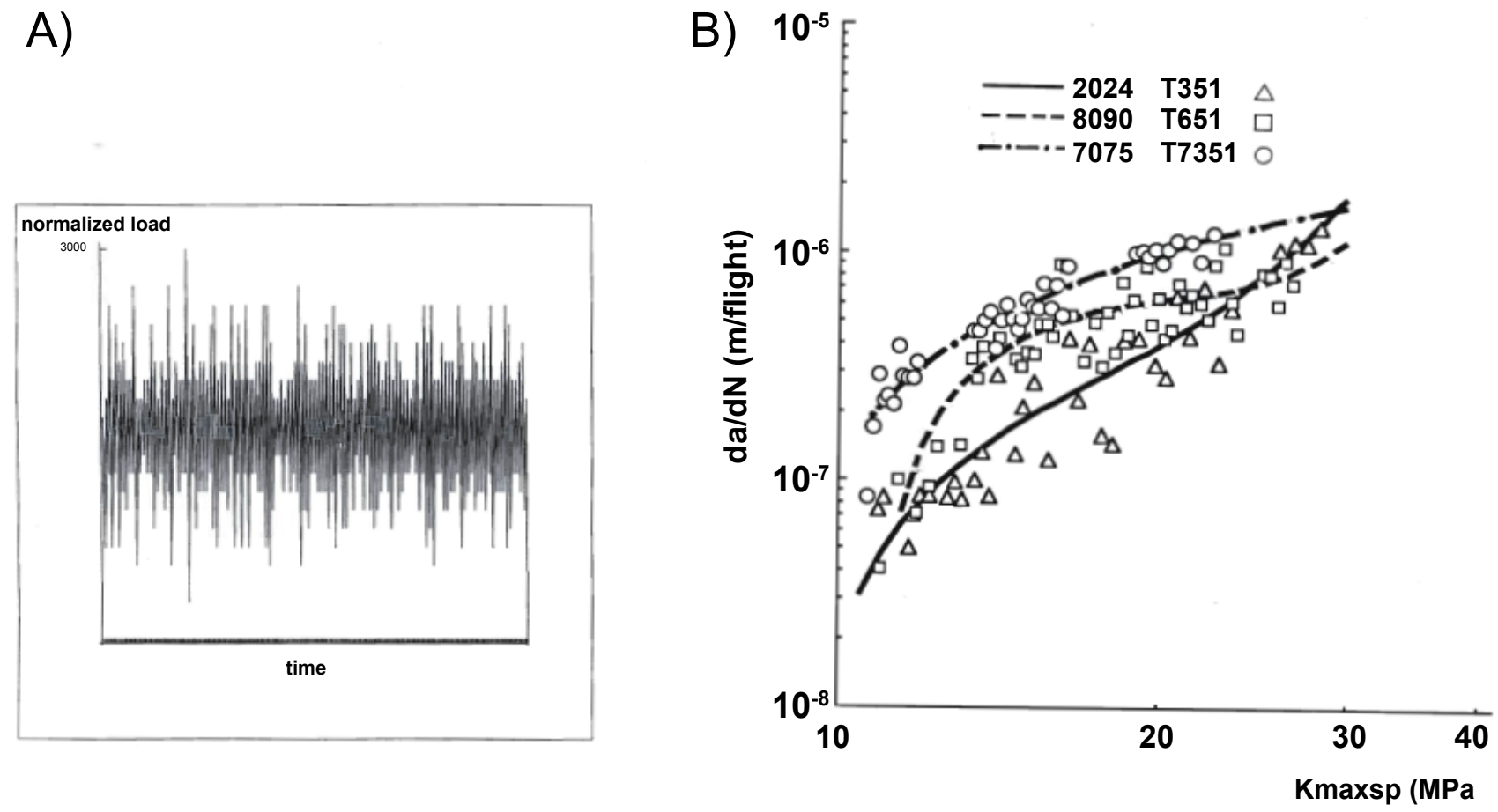

Figure 5: a) Most severe flight; b) Average crack growth rate.

alloys have similar behaviors. The Al-Li alloy has the best resistance in the $\Delta \mathrm{K}_{\mathrm{b}}$ range studied. The CA behavior at the base line loading, showed that the Al-Li alloy has the highest resistance while the other alloys had comparable resistances in the mid $\Delta \mathrm{K}_{\mathrm{b}}$ range. A similar classification is observed under repeated overload test but for the 7075 T351 alloy.

\section{Flight simulation loading}

The load spectrum is derived from a probabilistic analysis of the loads seen by an aircraft. The theoretical spectrum consists of 1000 different flights, each flight contains about 20 cycles [13]. The results for three selected alloys are given in Figure $5 \mathrm{a}$ and Figure $5 b$. In Figure $5 a$, the load variations for the most severe flight is shown. The loads, in $\mathrm{Y}$ axis are normalized (current load versus maximum load in the spectrum) values. $X$ axis represents time scale, the actual values depend upon the test frequency. In Figure 5b, the measured crack growth values are depicted with respect to $K_{\max }$ value in the spectrum. i.e., the $\mathrm{K}_{\max }$ value that occurs once in 22547 cycles. In facts in the tests described the maximum load was chosen to be $6000 \mathrm{~N}$ (corresponding to peak value of 1 ) and all other loads were scaled relative to this value. Considering this peak value, the $\mathrm{K}_{\text {maxsp }}$ varies from $10 \mathrm{Mpa} \mathrm{m}^{0.5}$ to $28 \mathrm{Mpa} \mathrm{m}^{0.5}$ as the crack length changes from 24 to $48 \mathrm{~mm}$.
Table 4: Crack growth lives in number of flights under the studied spectrum.

\begin{tabular}{|l|l|l|}
\hline 7075 T7351 & 8090 T651 & 2024 T351 \\
\hline 45625 & 89000 & 135000 \\
\hline
\end{tabular}

Scatter in crack growth in these tests is higher than that observed for CA tests. For instance crack growth rate varied from $710^{-8} \mathrm{~m} /$ flight to $210^{-7}$ $\mathrm{m} /$ flight for a $\mathrm{K}_{\text {maxsp }}$ of $15 \mathrm{Mpa} \mathrm{m}^{0.5}$. This scatter is much higher than what is conventionally observed under CA tests. The reason being, under variable amplitude loading load interaction effects may be present and $\mathrm{K}_{\text {maxsp }}$ does not represent the current $\mathrm{K}$ value at a given load and crack length.

It can be seen here that the 2024 alloy has the best crack growth resistance (better than the Al Li alloy), while the 7075 alloy has the least resistance.

Table 4 summarizes lives for crack growth from 24 to $43 \mathrm{~mm}$.

It is seen here that the 7075 alloy has the lowest life, and the 2024 T351 alloy the highest life. The Al li alloy has an intermediate Life. Thus comparing, constant amplitude, post Overload and Spectrum test, a change in behavior is observed for the Al $\mathrm{LI}$ alloy. 


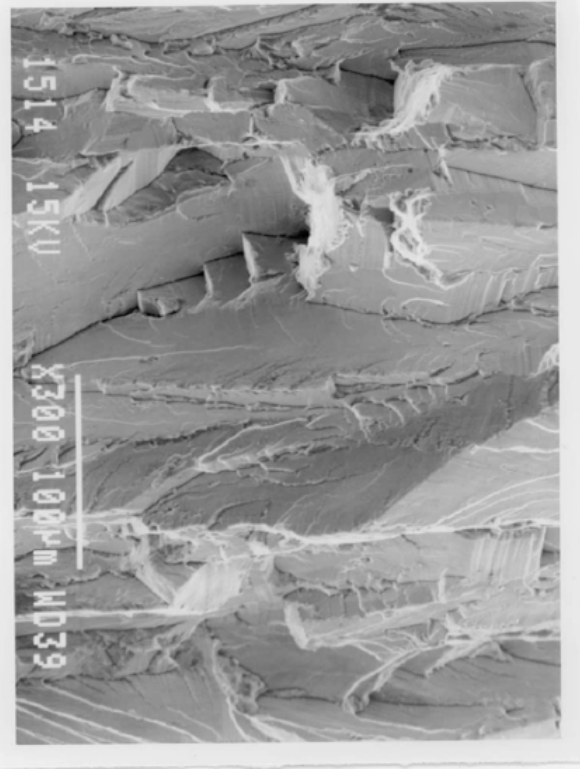

a)

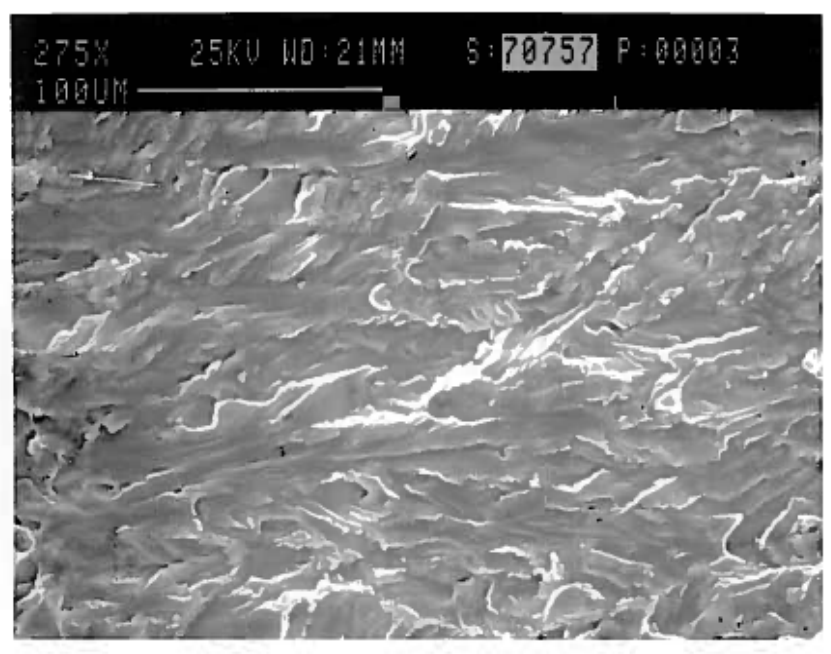

b)

Figure 6: a) Planar slip behavior; b) Multiple slip behavior.

\section{Discussion}

\section{Crack growth mechanisms}

The crack growth resistance is governed by the active slip systems at the crack tip. With respect to the 7075 alloy, in vacuum, the fracture surface is characteristic of planar slip behavior as seen Figure 6a, which shows the fracture surface. The appearance is very rough, growing along characteristic planes, probably of the (111) type, as seen in Figure 6a. The same kind of fracture surface appearance is observed in the 8090 alloy, tested in air.

In the case of multiple slip activity, the fracture surface is very flat and irrespective of the grain orientation, as seen in Figure $6 b[6,8,10]$.

The existence of a planar slip behavior, with characteristic zig zag cracking and leads to better crack growth resistance under constant amplitude and post overload conditions.

\section{Spectrum crack growth}

Crack growth under spectrum loading depends upon various factors such as intrinsic material behavior and possible load interaction effects such as retardation, acceleration or both. In the current study, the spectrum consist of one load excursion from about zero (In the tests the minimum load was about $100 \mathrm{~N}$ ) to the mean load (corresponding to cruise conditions). In this regime gust and maneuver loads are operating - They correspond to high load ratio cycles (see Figure 5a).

This configuration was analyzed using a root mean squared analysis to determine an equivalent constant amplitude loading using a root mean squared analysis $[14,15]$ :

$$
\begin{aligned}
& \operatorname{Pmax}_{\mathrm{rms}}=\frac{1}{N} * \sqrt{\sum_{1}^{N} P \max i^{2}} \\
& \operatorname{Pmin}_{\mathrm{rms}}=\frac{1}{N} * \sqrt{\sum_{1}^{N} P \min i^{2}}
\end{aligned}
$$

Where Pmaxi is the maximum load at cycle I and Pmini, the minimum load at cycle i.

We obtain thus an equivalent loading at a load ratio of 0.7 . The number of cycles $\mathrm{N}$ is 22 as we have approximately 22 cycles per flight. Thus one flight can be equated to a large Ground-air-Ground (GaG) cycle followed by 22 cycles at a load ratio of 0.7 - Figure 7.

Using this approach, we can now estimate the crack growth rate as

$\Delta \mathrm{a} /$ flight (est) $=\mathrm{da} / \mathrm{dN} \mathrm{GaG}+22(\mathrm{da} / \mathrm{dN})$ high load cycle.

Figure 8a compares measured and estimated crack growth rate for the 2024 alloy. One can see that the estimated growth rates are slightly higher than the measured ones. Figure $8 \mathrm{~b}$ compares the evolution of crack length to the number of flights. This analysis has been carried out for the 2024 alloy 


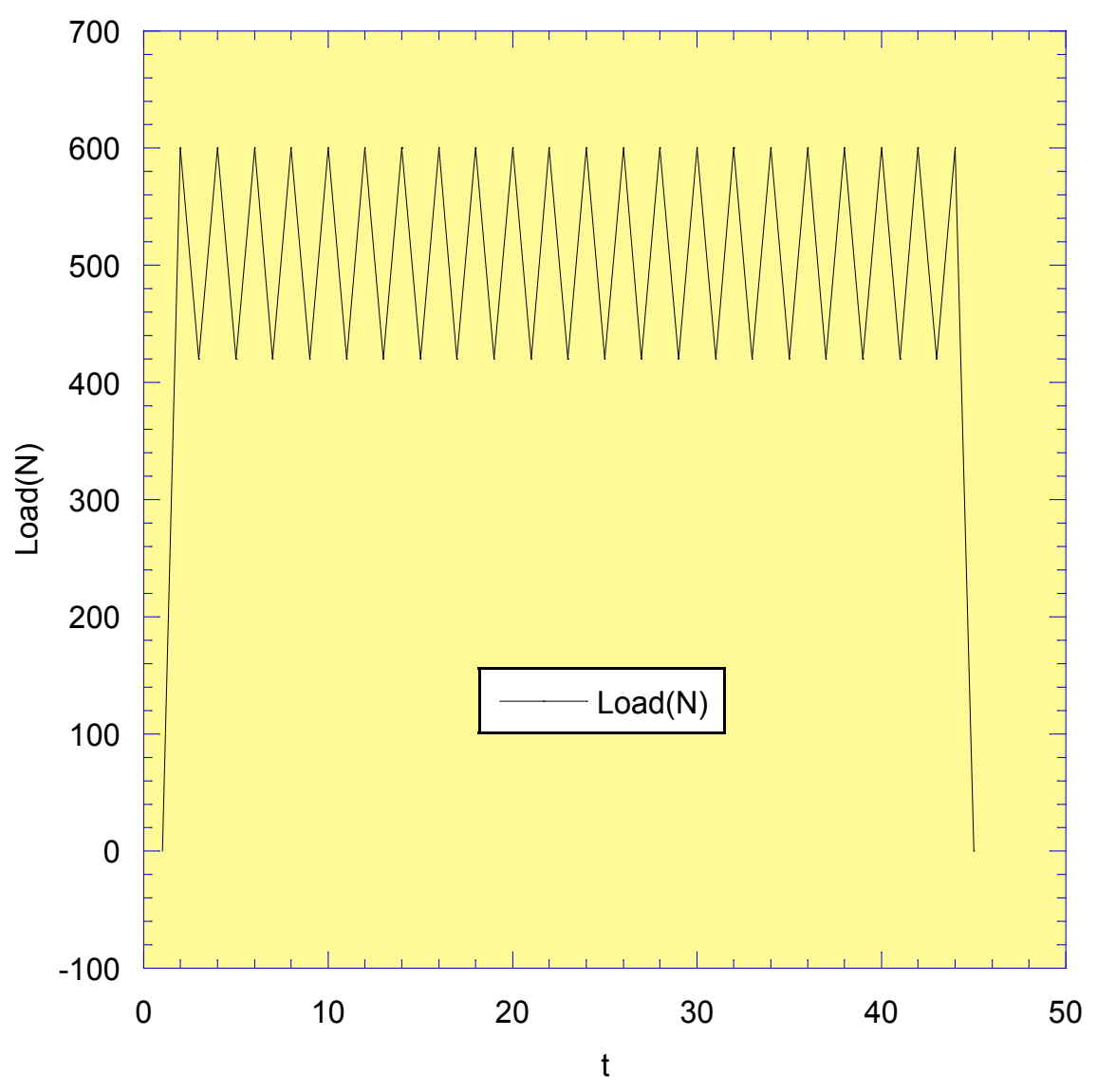

Figure 7: Equivalent flight - RMS analysis.

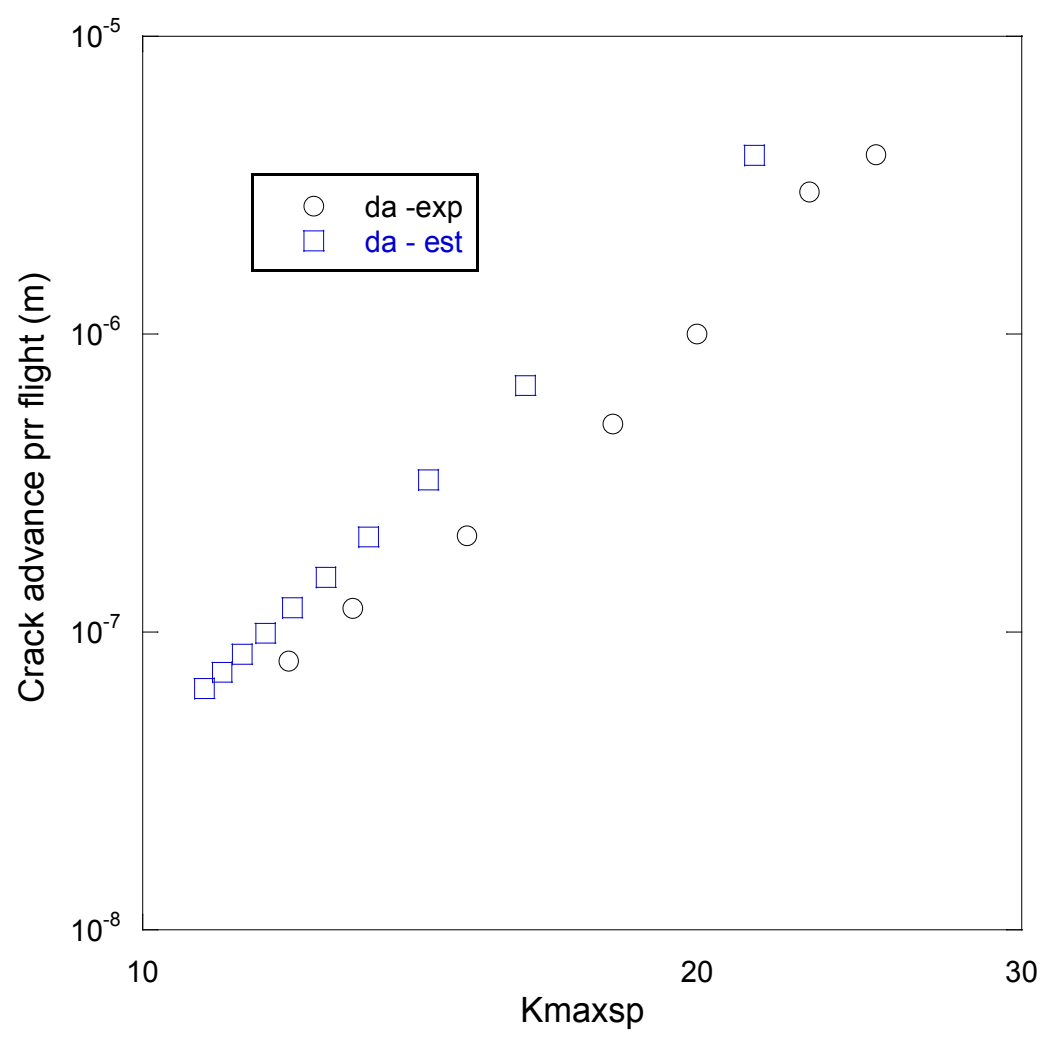

Figure 8a: Comparison of estimated and measured growth rates. 


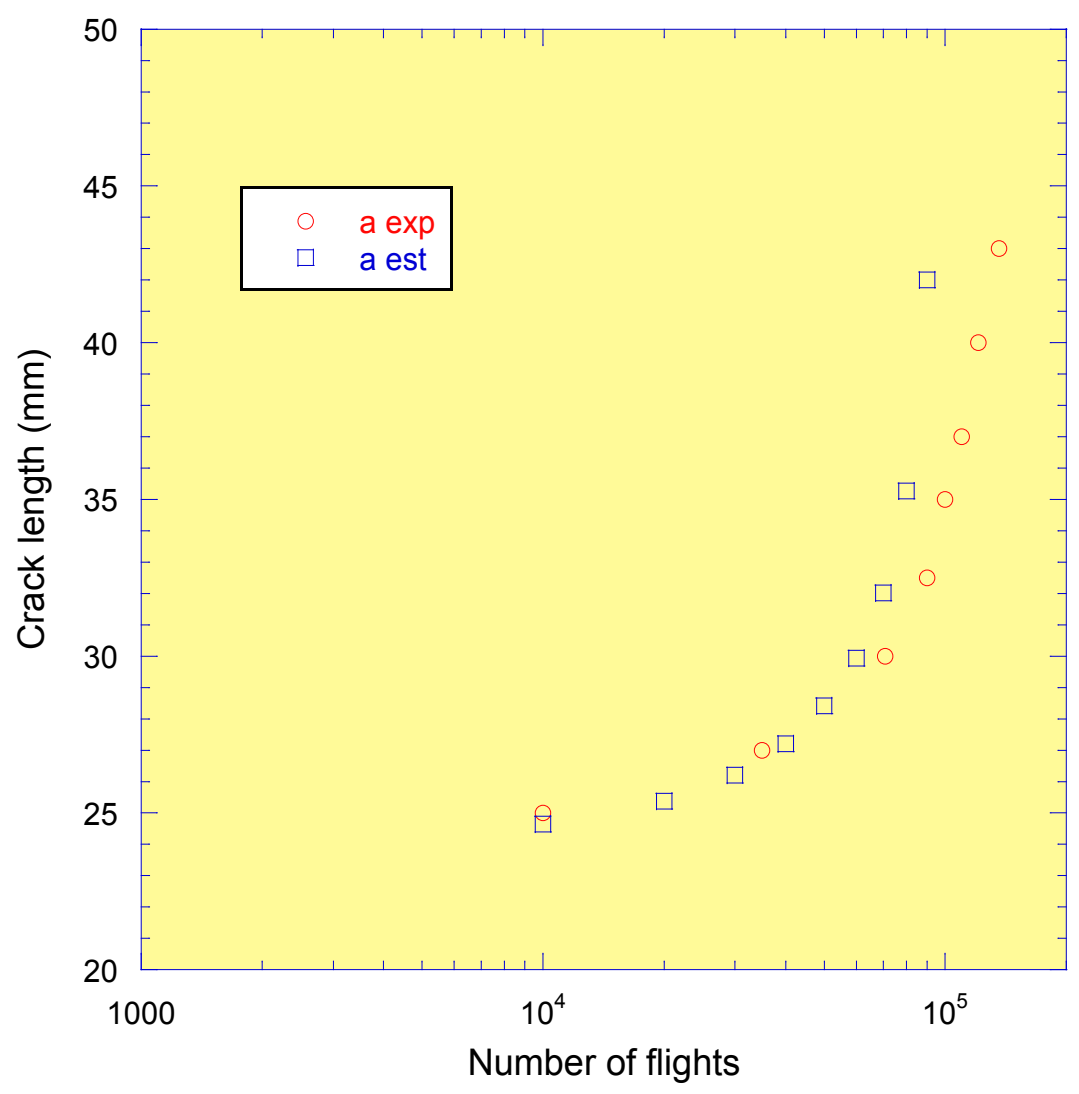

Figure 8b: Crack length versus number of flights -theory and experiments.

only.

The estimations are acceptable event though we have used a simplified approach to calculate the growth rate. The difference between the theory and experiments may be due to the presence of crack retardation effects not considered in the simplified model.

In the case of the 8090 alloy, under flight simulation loading, a change in cracking mechanism is observed, with the formation of a special kind of striation [16]. The formation of such striations results in a 4 fold crack acceleration, which explains the decrease in crack growth life of the Al Li alloy as compared to the 2024 alloy under spectrum loading.

\section{Conclusions}

Constant amplitude and variable amplitude fatigue crack growth resistance have been studied in the 7075 alloy in three heat treatments, the 2024 T351 alloy and the 8090 T651 Al-Li alloy.

In the 7075 alloy, in vacuum, highest threshold and lower near threshold growth rates are observed in the under-aged T351 condition. The overaged T7351 condition leads to lowest thresholds and near threshold crack growth resistance. The T651 condition has intermediate crack growth resistance.

For tests in air, the Al Li alloy has the highest resistance. The 2024 alloy has slightly lower resistance followed by the 7075 alloys.

For single overload and repeated overload tests, the same classification is observed as for constant amplitude near threshold behaviors.

The crack growth resistance depends upon material behavior. In general a material with planar slip behavior has a stronger fatigue crack resistance.

Under spectrum loading, the longest life is observed for the 2024 alloy and the shortest for the 7075 alloys.

The Al Li alloy tested here has a particular behavior under the aircraft spectrum loading tested here.

\section{References}

1. (2002) Standard test method for measurement of fatigue crack growth rates. ASTM E647, 603-644.

2. McKeighan PC (2015) Fatigue rack growth rate measurements - A review. In: Ranganathan N, 
Materials Characterization - Modern Methods and Applications. Pan Stanford Publications, 225-257.

3. Lowack H, Dejonge DC, Franz J, Schutz D (1979) MINITWIST: A shortened version of TWIST. NLR MP79018U, Netherlands.

4. McKeighan PC, McMaster F (2004) A framework for a standardization effort for fatigue crack growth testing under variable amplitude spectrum loading. McKeighan PC, Ranganathan N, ASTM STP 1439, West Conshohocken, USA, 36-52.

5. (2001) GENESIS 4 Fatigue CD: Generate standardized sequences. NLR Laboratories, Loads and fatigue Department, Emmelord, The Netherlands.

6. Ranganathan N (2015) Certain issues in variable amplitude fatigue. Procedia Engineering 101: 404412.

7. Tohru A, Gordon MB, Charles EB, Bruce AB, Tom B, et al. (1991) Heat treating. ASM Metals Handbook, ASM International, Metals Park Ohio, USA, 4.

8. Petit J, Tintillier R, Ranganathan N, Ait Abdedaim M, Chalant G (1988) Influence of microstructure and environment and environment on the post-overload fatigue crack propagation in high strength aluminium alloys fatigue crack growth under variable amplitude loading. In: Petit J, Elsevier publications, England, 162-179.

9. Ranganathan $N$, Benguediab $M$, Henaff $G$, Adiwijayento $F$ (1993) Quantitative fracture surface analysis of fatigue crack propagation under variable amplitude loading. In: John E Masters, Leslie N
Grilberton, ASTM STP 1203, Philadelphia, USA, 7194.

10.Petit J (1984) Fatigue crack growth threshold concepts. In: Davidson D, Suresh S, The TMS AIME publications, Philadelphia, USA, 3-24.

11.Von Euw EFJ, Hertzberg RW, Roberts R (1972) Stress analysis and growth of cracks. ASTM STP 513, West Conshohocken, USA, 230-259.

12.Ranganathan N, Tougui A, Lacroix FN, Petit J (2004) Overload effects in aluminum alloys: Influence of plasticity and environment. ASTM STP 1439, West Conshohocken, USA, 468-451.

13. Bleuzen C, Chaudonneret M, Farcy L, Flavenot JF, Ranganathan N (1994) Fatigue testing and life prediction for notched specimens of 2024 and 7010 alloys subjected to aeronautical spectra. ASTM STP 1231, USA, 504-526.

14. Hudson CM (1981) A root mean squared approach for predicting fatigue crack growth under random loading. ASTM STP 748, Philadelphia, USA, 41-52.

15.Ranganathan N, Desforges JR (1996) Equivalent constant amplitude concepts examine under fatigue crack propagation by block loading. Fatigue Fract Engng Mater Struct 19: 997-1008.

16. Ranganathan N, Adiwijayanto F, Petit J, Bailon JP (1995) Fatigue crack propagation mechanisms in an aluminium lithium alloy. Acta Metallurgica et Materialia 43: 1029-1035. 